\title{
Tobacco smoking by adult emergency department patients in Australia: a point-prevalence study
}

\author{
Tracey J Weilanda,b,d, George A Jelineka,b, Simone E Taylor ${ }^{\mathrm{c}}$ and David \\ McD Taylorb,c
}

${ }^{a}$ Emergency Practice Innovation Centre, St Vincent's Hospital Melbourne, Victoria, Australia

b Faculty of Medicine, Dentistry and Health Sciences, The University of Melbourne, Victoria, Australia

c Department of Emergency Medicine, Austin Health, Melbourne, Victoria, Australia

${ }^{d}$ Corresponding author: tracey.weiland@svha.org.au

\section{Article history}

\section{Publication date: July 2016}

Citation: Weiland TJ, Jelinek GA, Taylor SE, Taylor DMcD. Tobacco smoking by adult emergency department patients in Australia: a point-prevalence study. Public Health Res Pract. 2016;26(3):e2631634. doi: http:// dx.doi.org/10.17061/phrp2631634

\section{Key points}

\section{- Smoking prevalence in the genera} Australian population ranges from approximately $13 \%$ to $17.5 \%$

- International data demonstrate higher rates of smoking among emergency department (ED) patients than the general population

- Consistent with international data, we report the smoking prevalence among the adult ED patient population to be $23.3 \%$, with desire for cessation at $69.7 \%$

- $60.3 \%$ of smokers were willing to undergo brief counselling for cessation

- Following validation of these data, EDs may represent strategic locations from which smoking cessation programs should be initiated

\section{Abstract}

Objectives and importance of study: Tobacco smoking is the leading single cause of preventable death. International findings suggest that rates of smoking are higher among emergency department (ED) patients than the general population, suggesting that the ED may be a strategic location in which to initiate smoking cessation programs. We aimed to determine the prevalence of smoking among adult ED patients in Australia, their desire for smoking cessation and preferred methods of cessation.

Study type: Point-prevalence survey

Method: A sample of adult ED patients was recruited from two tertiary referral hospital EDs. Participants were asked whether or not they currently smoked. Smokers were asked 15 additional questions, including about their readiness for smoking cessation. Demographics were collected from patients, and ED presentation characteristics were collected from medical records.

Results: Of 443 consecutive ED patients, 348 were eligible and 338 consented to participate. Data for 335 participants were available for analysis and 78 (23.3\%; 95\% confidence interval [Cl] 19.1, 28.1) reported being current smokers. The mean age of smokers was 42.1 years, and $64.1 \%$ were male. Forty-one per cent (31/75) reported difficulty refraining from smoking, $78.1 \%$ (57/73) anticipated health problems because of smoking and 69.7\% (53/76) had a desire to quit. Overall, $23 / 61$ (37.7\% of smokers) had a desire to cease smoking in the next month. The majority $(44 / 73,60.3 \%)$ were willing to undergo brief counselling. Multisession face-to-face counselling was most commonly preferred (22/55, 40.0\%) and more than one-third (20/55, 36.4\%) preferred group counselling. A session with an ED doctor (6/55, 10.9\%) and multiple telephone-delivered interventions (7/55, 12.7\%) were least preferred.

Conclusion: Smoking is more prevalent among ED patients than statistics reported for the general population. Delivery of appropriate brief interventions suited to the stage of change should be trialled, along with referral from ED to counselling services. 


\section{Introduction}

Tobacco smoking is the largest preventable cause of death in the world ${ }^{1}$, and represents a key risk factor for death from ischaemic heart disease and cancer. ${ }^{1}$ Worldwide, approximately 1 in 10 adult deaths is attributable to tobacco ${ }^{1}$, and every year, approximately 15000 Australians die because of tobacco use. ${ }^{2}$ Recent Australian population data suggest that up to two-thirds of deaths among current smokers are attributable to smoking. ${ }^{3}$ Tobacco smoking accounts for $7.8 \%$ of the total burden of disease in Australia, the highest among 14 risk factors examined. ${ }^{2}$ Put simply, tobacco causes more disease in Australia than any other risk factor. ${ }^{2}$

Daily smoking rates in the general Australian population range between $13 \%{ }^{4}$ and $17.5 \% .^{5}$ Although the prevalence among Australian emergency department (ED) patients is unknown, international data suggest higher rates among ED patients than the general population. ${ }^{6}$ Internationally, the prevalence of smoking among ED patients is reported to vary between $21 \%$ and $41 \%$. $^{7,8}$

Smoking cessation significantly reduces all-cause mortality ${ }^{3}$ and the risk of disease. Since the prevalence among ED patients typically exceeds that of the general population, and given ED patients may be more receptive to change because of their morbidity status ${ }^{6}$, EDs have been highlighted as strategic locations from which to facilitate smoking cessation. A systematic review revealed that ED visits in combination with ED-initiated tobacco cessation interventions were associated with higher rates of cessation than those reported in the National Health Interview Survey. ${ }^{6}$

Although effective strategies to facilitate smoking cessation exist ${ }^{9}$, there is no unified cessation approach adopted by Australian hospitals or EDs, aside from smoke-free policies. In Australia, there are, to our knowledge, no data regarding smoking prevalence among ED patients or associated factors. One study of inpatients, however, revealed both a high motivation to quit and readiness to change, and a belief in the efficacy of nicotine replacement therapy (NRT). ${ }^{10}$ Smokers who participated in this large multisite study were typically older, English-speaking, Australian-born males, with hospital admission most commonly because of circulatory disorders. ${ }^{10}$ With the exception of inpatients ${ }^{10}$, little is known regarding intervention preferences for patients receiving hospital care.

In the context of the busy ED, a practical approach to smoking cessation should involve determination of the patient's stage of change (SOC) - that is, their readiness for cessation. ${ }^{11}$ Although this concept is not without contention ${ }^{12}$, some evidence suggests that interventions targeted to the patient's SOC yield greater success. ${ }^{11}$ Garnered in one or two simple questions, SOC information can guide interventions suited to patients (e.g. information-only or action-oriented), producing a targeted approach that may be more economical than a blanket approach

In the absence of available statistics for the Australian ED population, the primary objective of this study was to determine the prevalence of smoking among adult patients presenting to the ED (primary outcome). Secondary aims were to determine ED smokers' heaviness of smoking, their SOC and preferred interventions; and to explore factors associated with smoking.

\section{Method}

\section{Study design}

A multisite point-prevalence survey was undertaken of adult ED patients.

\section{Setting}

The study was undertaken in December 2010 in the EDs of St Vincent's Hospital Melbourne (STV) and the Austin Hospital (AH). In 2010, STV's ED had an annual patient census of approximately 40000 adults, and the $\mathrm{AH}$ received approximately 47000 adult patients.

\section{Participant eligibility and study period}

Patients were eligible to participate if they were at least 18 years old and presented to the ED during the study period. Patients were ineligible if they:

- Were unable to consent

- Did not speak sufficient English

- Left without being seen by an emergency physician

- Were unfit to consent (e.g. because they were intoxicated, had a cognitive impairment or were highly dependent on medical care).

\section{Procedure}

We sought a sample of 350 patients recruited in equal numbers from STV and $\mathrm{AH}$. Participants were recruited by a single medical graduate. STV patients were recruited during a 36-hour period from 9.30 am on 9 December 2010, and $\mathrm{AH}$ patients were recruited during the 30-hour period from 10 am on 16 December 2010.

Eligible patients were approached in the ED and invited to participate. Those deemed by the treating doctor to be medically unstable or highly dependent on medical care were approached later in their ED stay if they became sufficiently stable to participate. Patients were given a participant information form describing the study and consent process. Survey participation was taken as implied consent. Consenting patients were verbally administered a questionnaire (Box 1), which took 1-5 minutes to complete.

Most items were derived from validated tools, including the Fagerström Test for Nicotine Dependence $(\mathrm{FTND})^{13}$, the Heaviness of Smoking Index $(\mathrm{HSI})^{14}$ and 
Box 1. Smoking study questionnaire

Please answer the following:

What is your current age in years and months? years and months

What is your gender? (tick one)

$\square$ Male

$\square$ Female

Where were you born?

What is your current employment status? (tick one only)

$\square$ Employed

$\square$ Student

$\square$ Unemployed

$\square$ Homemaker/parental duties

$\square$ Retired/long-term disabled

Do you currently smoke cigarettes?

$\square$ No $\Rightarrow$ Thankyou, your participation in the study is complete. Please return the survey to the researcher.

$\square$ Yes $\Rightarrow$ Continue survey below

\section{Continue answering questions below only if you currently smoke cigarettes}

How old were you when you started smoking?

How soon after you wake up do you smoke your first cigarette? (tick one only ) years
$\square$ Within 5 minutes
$\square$ 6-30 minutes after
$\square$ 31-60 minutes after
$\square$ After 60 minutes

Do you find it difficult to refrain from smoking in the places where it is forbidden?

Which cigarette would you hate most to give up?

Do you smoke more frequently during the first hours after waking than the rest of the day? $\square$ No

$\square$ Yes

$\square$ The first one in the morning

$\square$ Any other

$\square$ No

$\square$ Yes

How many cigarettes do you usually smoke a day?

Do you anticipate health problems related to smoking?

$\square \mathrm{No}$

$\square$ Yes

Do you want to quit smoking in the next 6 months?

$\square$ Yes $\Rightarrow$ Do you intend to quit in the next month?

$\square$ Yes

$\square$ No

$\square$ No $\Rightarrow$ Would you like to quit if it was easy?

$\square$ Yes

$\square$ No

$\square$ Unsure

Have you tried to stop smoking before?

$\square$ No

$\square$ Yes $\Rightarrow$ How many times:

Would you be willing to undergo a brief counselling session in the emergency department to assist you in quitting if this service were available?

$\square$ Yes

$\square$ No

Would raising the cost of cigarettes to $\$ 20$ per pack assist you in quitting?

$\square$ Yes

$\square$ No

If they were available, what sort of program would you prefer to assist you in quitting? (tick one only)

$\square$ One session delivered by the emergency department doctor

$\square$ Multisession face to face counselling

$\square$ Multisession telephone counselling

$\square$ Group counselling 
the Readiness to Quit Ladder ${ }^{15}$, although the entire questionnaire itself was not validated before use. Participants were asked basic demographics (age, gender, country of birth, employment status). To assess smoking prevalence, they were asked the researcherderived question "Do you currently smoke cigarettes? (yes/no)". This item is similar to that used by others ${ }^{7,8}$ for which reliability has been demonstrated. ${ }^{8}$ Participants were not provided with a definition of smoking. Smokers were asked up to 15 further questions, including five items from the FTND ${ }^{13}$ and researcher-devised questions about the age of smoking commencement, anticipation of smoking-related health problems, willingness to undergo counselling and previous quitting attempts. Questions eliciting SOC were also included, using the Readiness to Quit Ladder with 10 response options. ${ }^{15}$ Participants were also asked their preference for cessation intervention: "If they were available, what sort of program would you prefer to assist you in quitting?", with four response options. Face validity of researcher-derived items were assessed iteratively by the researchers.

Two items from the FTND (time to first cigarette after waking and number of cigarettes smoked daily) were used to calculate the HSI. These have high predictive value for the complete FTND. We adopted a previously used $^{14}$ classification system for the HSI total score: low $(<2)$, medium (2-4), and high (>4). Smokers of low HSI are most likely to report quitting, and those of high $\mathrm{HSI}$, given a sufficient duration, are more likely than moderate $\mathrm{HSI}$ smokers to report cessation. ${ }^{14}$

Further data regarding participants' ED presentation characteristics were obtained from electronic medical records. These data were matched to participant data using the patients' self-reported age, time of attendance and unique identifier. Clinical data retrieved included arrival mode, Australasian Triage Scale code indicating urgency, and presenting complaint. These data are routinely entered electronically by nurses trained in ED triage, are reported to health authorities and undergo internal audit. Some $(n=4)$ omitted some demographic data elements, whereas others completed some, but not all, survey items. Additionally, 10 cases for which demographic data were supplied could not be matched to their clinical record. Data for presenting complaint were categorised by an emergency physician (co-author GAJ) with experience in triage and presenting complaint research as "Presenting complaint has been associated with or exacerbated by smoking" or "Not associated with smoking/indeterminate". Complaints associated with, or exacerbated by, smoking were consistent with those described in burden of disease data, and included symptoms of diseases of the cardiovascular, cerebrovascular and respiratory systems, and presentations related to cancer or diabetes. Continuous data for age were categorised (18.00-30.99; 31-50.99; 51-70.99; >70.99) to explore prevalence by age.

\section{Sample size and data analyses}

The primary outcome was the prevalence of cigarette smoking among ED patients. Given published reports ${ }^{7}$ and national statistics ${ }^{4,5}$, we estimated smoking prevalence among ED patients to range between 20\% and $30 \%$, and estimated the sample size based on the upper figure. To estimate the proportion to a $5 \%$ level of precision, 318 participants needed to be recruited; therefore, we sought a sample size of 350 .

Data were analysed using SPSS 20.0 (Chicago, US). Data were described using frequency analyses (number and proportions, 95\% confidence interval [Cl]) for categorical data. Means and 95\% Cls were used for continuous variables after first assessing normality, and medians and interquartile ranges (IQR) were used where data were not normally distributed. Exploratory analyses were undertaken using Pearson's chi-square test and Fisher's exact test to assess the presence of significant associations between smoking status, and patient clinical and demographic features (age group, gender, employment status, mode of arrival to hospital, triage scale, and whether the presenting complaint is associated with, or exacerbated by, smoking). Percentages reported are adjusted for missing data such that denominators reflect actual respondents. Demographics of survey respondents were compared with other patients attending during the month of testing to assess sample representativeness. Significance was set at 0.05 and two-tailed tests were used. No adjustments were made for multiple comparisons.

\section{Ethics}

The ethics committee of each participating hospital approved the study.

\section{Results}

\section{Participation}

A total of 198 and 245 ED attendances were recorded for the study periods at STV and $\mathrm{AH}$, respectively. Overall, $338 / 348(97.1 \%)$ that were eligible for participation responded (Figure 1).

\section{Demographics}

Participant demographics and ED presentation characteristics are provided in Table 1. A total of 52 countries of birth were represented, including 206 (61.5\%) Australian-born participants. Participants were mainly employed or retired.

\section{Smoking prevalence}

Of 335 participants, 78 (23.3\%; 95\% Cl 19.1, 28.1) reported currently smoking. Prevalence varied significantly with gender, employment status and age 
Figure 1. Flowchart of participation

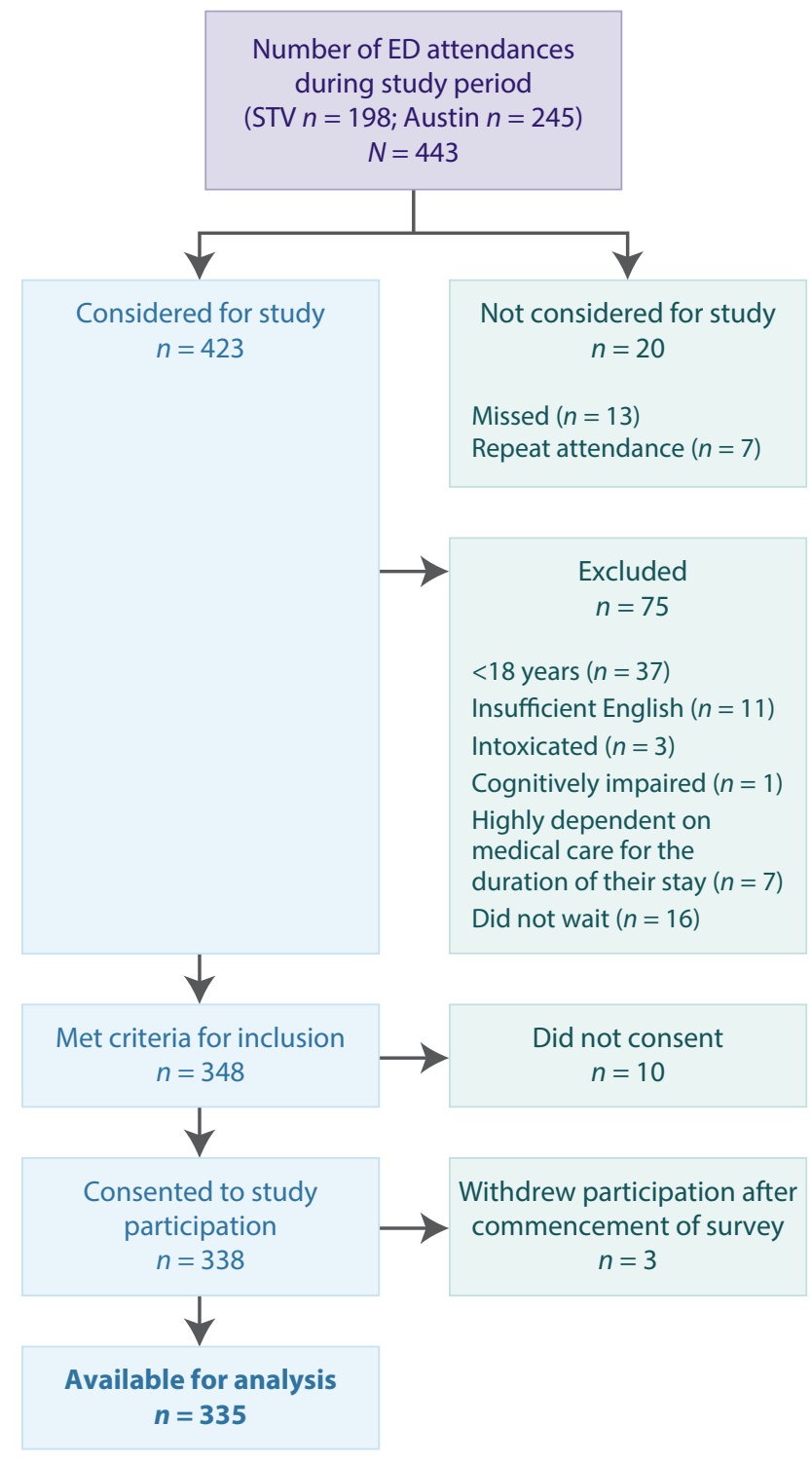

Austin = Austin Hospital; ED = emergency department; STV = St Vincent's Hospital Melbourne

(Table 2). Although smoking status was unrelated to arrival mode or having a smoking-associated presenting complaint, it was related to urgency of presentation - category 4 patients were significantly overrepresented among smokers. Approximately twothirds of smokers were male and mean age of smoking commencement was 16.5 years $(95 \% \mathrm{Cl} 15.6,17.3)$.

The majority reported smoking their first cigarette of the day within 30 minutes of waking (Table 3). Approximately half $(37 / 71 ; 52.1 \%$; 95\% Cl 40.7, 63.3) nominated the first cigarette of the day as the one they would most hate to give up. Half (37/73; 50.7\%; 95\% $\mathrm{Cl} 39.5,61.8)$ indicated smoking more frequently in the first hours after waking compared with the remainder of the day.

\section{Heaviness of Smoking Index}

Smokers had mixed HSI levels:

- Low range - 20/71 (28.2\%; 95\% Cl 19.0, 39.6)

- Moderate range - 39/71 (54.9\%; 95\% Cl 43.4, 66.0)

- High range - 12/71 (16.9\%; 95\% Cl 9.8, 27.4).

\section{Readiness for change}

Thirty-one out of 75 smokers (41.3\%; 95\% Cl 30.9, 52.6) reported difficulty refraining from smoking where it is forbidden, 57/73 (78.1\%; 95\% Cl 67.2, 86.1) anticipated smoking-related health problems, and 53/76 (69.7\%; 95\% $\mathrm{Cl} 58.6,79.0)$ had a desire to quit in the next 6 months. An intention to quit in the next month was indicated by 23/61 (37.7\%; 95\% Cl 26.6, 50.3) for all smokers; and $23 / 51$ (45.1\%; $95 \% \mathrm{Cl} 32.3,58.6$ ) of those wishing to quit. Of those intending to quit in the next month, 19/23 (82.6\%; $95 \% \mathrm{Cl} 62.3,93.6$ - or $82.6 \%$ of all smokers) had already attempted to quit previously. Of those indicating no desire to quit, $9 / 20(45.0 \% ; 95 \% \mathrm{Cl} 25.8,65.8)$ indicated they would not like to quit even if quitting were easy. Overall, $64 / 75$ (85.3\%; 95\% Cl 75.4, 91.8) of the participants had previously attempted to quit. The median number of quit attempts was 3 (IQR 2-4).

\section{Intervention preferences}

The majority (44/73; 60.3\%; 95\% Cl 48.8, 70.7) indicated a willingness to undergo brief counselling in the ED; however, when presented with a range of possible interventions, having a single session with an ED doctor was least preferred $(6 / 55,10.9 \%)$, followed by multiple sessions by phone $(7 / 55,12.7 \%)$. Approximately onethird preferred group counselling (20/55, 36.4\%) and $40.0 \%$ preferred multisession face-to-face counselling (22/55, 40.0\%).

\section{Discussion}

\section{Smoking prevalence}

Although ED-based smoking interventions have been recommended internationally ${ }^{6,7,8}$, prevalence statistics have, to date, been lacking for the Australian ED population, thereby precluding local recommendations. To our knowledge, this is the first study of its kind in Australia. It documents the smoking prevalence and patterns among Australian adult ED patients. Like others ${ }^{7}$, we found that smoking is prevalent among ED patients. In our sample, 23\% reported being current smokers. Although some estimates of smoking prevalence have used self-completed questionnaires ${ }^{7}$, we used face-toface interviewing, which may have underestimated the prevalence. Our estimates are considerably lower than New Zealand figures of $33 \%^{7}$, but higher than those reported for the general population of adult Australians in $2011-12^{16}$ (18.1\% smokers and $16.8 \%$ daily smokers), 
Table 1. Participants' demographics and emergency department presentation characteristics

\begin{tabular}{|c|c|c|c|}
\hline Category & Variable & Study sample & Population of adults attending study sites ${ }^{a}$ \\
\hline \multirow[t]{2}{*}{ Gender } & Male & $176(52.5 ; 47.2,57.8)$ & $4421(52.0)$ \\
\hline & Total respondents & $335(100.0)$ & $8498(100.0)$ \\
\hline \multirow[t]{2}{*}{ Age } & Years, mean $(95 \% \mathrm{Cl})$ & $50.0(47.7,52.3)$ & $52.3(51.8,52.7)$ \\
\hline & Total respondents & $332(100.0)$ & $8498(100.0)$ \\
\hline \multirow[t]{5}{*}{ Age group } & 18.00-30.99 & $89(26.8 ; 22.3,31.8)$ & $1776(20.9)$ \\
\hline & $31.00-50.99$ & $92(27.7 ; 23.2,32.8)$ & $2446(28.8)$ \\
\hline & 51.00-70.99 & $71(21.4 ; 17.3,21.1)$ & $2156(25.4)$ \\
\hline & $>70.99$ & $80(24.1 ; 19.8,29.0)$ & $2119(24.9)$ \\
\hline & Total respondents & $332(100.0)$ & $8498(100.0)$ \\
\hline \multirow[t]{6}{*}{ Mode of arrival ${ }^{b}$} & Road ambulance & $102(31.4 ; 26.6,36.6)$ & $2316(27.3)$ \\
\hline & Private ambulance & $6(1.8 ; 0.8,4.1)$ & $146(1.7)$ \\
\hline & Air ambulance & $0(0.0)$ & $4(0.0)$ \\
\hline & Police & $0(0.0)$ & $53(0.6)$ \\
\hline & Other ${ }^{\mathrm{c}}$ & $217(66.8 ; 61.5,71.7)$ & $5979(70.4)$ \\
\hline & Total respondents & $325(100.0)$ & $8498(100.0)$ \\
\hline \multirow{6}{*}{$\begin{array}{l}\text { Australasian Triage Scale } \\
\text { code }^{b}\end{array}$} & 1 - see immediately & $3(0.9 ; 0.2,2.8)$ & $90(1.1)$ \\
\hline & 2 - see within $10 \mathrm{~min}$ & $37(11.4 ; 8.3,15.3)$ & $1247(14.7)$ \\
\hline & 3 - see within $30 \mathrm{~min}$ & $137(42.2 ; 36.9,47.6)$ & $3409(40.1)$ \\
\hline & 4 - see within $60 \mathrm{~min}$ & $118(36.3 ; 31.3,41.7)$ & $3164(37.2)$ \\
\hline & 5 - see within $120 \mathrm{~min}$ & $30(9.2 ; 6.5,12.9)$ & $588(6.9)$ \\
\hline & Total respondents & $325(100.00)$ & $8498(100.00)$ \\
\hline \multirow[t]{6}{*}{ Employment status } & Employed & $138(41.9 ; 37.0,47.7)$ & Data not collected \\
\hline & Retired/pension & $114(34.7 ; 29.7,40.0)$ & \\
\hline & Student & $32(9.7 ; 6.9,13.4)$ & \\
\hline & Homemaker/parent & $30(9.1 ; 6.4,12.8)$ & \\
\hline & Unemployed & $15(4.6 ; 2.7,7.4)$ & \\
\hline & Total respondents & $329(100.0)$ & \\
\hline
\end{tabular}

a In December 2010

b Total $N=325$; data missing because of inability to match survey data to electronic patient record

c Includes public transport, car, taxi, walked

Note: Data shown are number (\%, 95\% confidence interval) unless otherwise stated

and $16.8 \%$ reported in 2010 for the general Victorian population. ${ }^{17}$ Given the annual ED attendance throughout Australia, this 5-6\% difference translates to a substantial number of people, giving ED-initiated interventions a 'high reach' on a population level. Although requiring validation in a nationally representative, multisite ED sample, our data suggest that smoking prevalence was greatest in those aged $31-50$ years (males $41.7 \%$; females $42.9 \%$ ) and in those of lower acuity. In contrast, 2010 Victorian population health data ${ }^{17}$ found that smoking prevalence was greatest for males aged 25-35 (23.9\%) and females $18-24$ years $(21.7 \%)$. There is significant potential, therefore, to target a different population with a substantially higher smoking prevalence.

\section{Heaviness of Smoking Index}

Just less than half our sample was categorised as having low or high $\mathrm{HSI}$, and therefore may have been highly likely to have sustained smoking cessation should an intervention have been provided. The odds of smoking cessation have been demonstrated to be higher among those with low and high HSI compared with medium $\mathrm{HSI}^{14}$. Although the $\mathrm{HSI}$ is thought to be an indicator of nicotine dependence, there is likely to be a range of other mediating factors for cessation. ${ }^{14}$

One in five smokers in our sample presented with a condition that could be associated with, or exacerbated by, smoking. Having such a condition did not, however, differentiate between smokers and nonsmokers. Although our study was not powered to explore preferences or attitudes within this subgroup, a US study of 10 EDs revealed receptivity to ED-based cessation interventions was independently predicted by self-reporting smokingrelated symptoms. ${ }^{18}$ This is an important avenue to explore further and may assist in developing a targeted screening strategy. 
Table 2. Characteristics associated with cigarette smoking in emergency department patients

\begin{tabular}{|c|c|c|c|c|}
\hline Variable & Category & Smokers & Nonsmokers & $p$ value \\
\hline \multirow[t]{2}{*}{ Gender, $n=335$} & Male & $50(64.1)$ & $126(49.0)$ & \multirow[t]{2}{*}{0.020} \\
\hline & Female & $28(35.9)$ & $131(51.0)$ & \\
\hline Age, mean, $n=332$ & & 42.1 & 52.0 & $<0.001$ \\
\hline \multirow[t]{4}{*}{ Age group } & 18.00-30.99 & $22(28.9)$ & $67(26.2)$ & \multirow[t]{4}{*}{$<0.001$} \\
\hline & $31.00-50.99$ & $32(42.1)^{a}$ & $60(23.4)^{b}$ & \\
\hline & 51.00-70.99 & $16(21.1)$ & $55(21.5)$ & \\
\hline & $>70.99$ & $6(7.9)^{\mathrm{b}}$ & $74(28.9)^{a}$ & \\
\hline \multirow[t]{4}{*}{ Males by age group } & 18.00-30.99 & $16(33.3)$ & $32(25.4)$ & \multirow[t]{4}{*}{0.013} \\
\hline & $31.00-50.99$ & $20(41.7)^{a}$ & $29(23.0)^{b}$ & \\
\hline & 51.00-70.99 & $7(14.6)$ & $32(25.4)$ & \\
\hline & $>70.99$ & $5(10.4)^{b}$ & $33(26.2)^{a}$ & \\
\hline \multirow[t]{4}{*}{ Females by age group } & $18.00-30.99$ & $6(21.4)$ & $35(26.9)$ & \multirow[t]{4}{*}{0.006} \\
\hline & $31.00-50.99$ & $12(42.9)^{a}$ & $31(23.8)^{b}$ & \\
\hline & $51.00-70.99$ & $9(32.1)$ & $23(17.7)$ & \\
\hline & $>70.99$ & $1(3.6)^{b}$ & $41(31.5)^{\mathrm{a}}$ & \\
\hline \multirow[t]{5}{*}{ Employment status, $n=329$} & Unemployed & $7(9.1)^{\mathrm{a}}$ & $8(3.2)^{b}$ & \multirow[t]{5}{*}{0.001} \\
\hline & Homemaker & $10(13.0)$ & $20(7.9)$ & \\
\hline & Employed & $41(53.2)^{\mathrm{a}}$ & $97(38.5)^{b}$ & \\
\hline & Student & $7(9.1)$ & $25(9.9)$ & \\
\hline & Retired/pensioner & $12(15.6)^{b}$ & $102(40.5)^{\mathrm{a}}$ & \\
\hline \multirow[t]{5}{*}{ Australasian Triage Scale code, $n=325$} & 1 - see immediately & $1(1.3)$ & $2(0.8)$ & \multirow[t]{5}{*}{$0.013^{\circ}$} \\
\hline & 2 - see within $10 \mathrm{~min}$ & $6(8.0)$ & $31(12.4)$ & \\
\hline & 3 - see within $30 \mathrm{~min}$ & $23(30.7)^{b}$ & $114(45.6)^{\mathrm{a}}$ & \\
\hline & 4 - see within 60 min & $35(46.7)^{\mathrm{a}}$ & $83(33.2)^{b}$ & \\
\hline & 5 - see within $120 \mathrm{~min}$ & $10(13.3)$ & $20(8.0)$ & \\
\hline \multirow[t]{3}{*}{ Mode of arrival, $n=325$} & Road ambulance & $22(29.3)$ & $80(32.0)$ & \multirow[t]{3}{*}{0.900} \\
\hline & Private ambulance & $1(1.3)$ & $5(2.0)$ & \\
\hline & Own transport/other ${ }^{d}$ & $52(69.4)$ & $165(66.0)$ & \\
\hline \multirow{2}{*}{$\begin{array}{l}\text { Smoking-related presenting complainte } \\
n=325\end{array}$} & Unrelated/indeterminate & $60(80.0)$ & 207 (82.8) & \multirow[t]{2}{*}{0.607} \\
\hline & $\begin{array}{l}\text { Presenting complaint } \\
\text { associated with smoking }\end{array}$ & $15(20.0)$ & $43(17.2)$ & \\
\hline
\end{tabular}

a Significantly overrepresented according to standardised adjusted residuals

b Significantly underrepresented according to standardised adjusted residuals

c Linear association

d Includes public transport, car, taxi, walking

e Having a presenting complaint considered by an emergency physician to be associated with or exacerbated by smoking

Note: Data shown are number (\%)

\section{Readiness for change}

The optimal group to focus on when facilitating cessation through the ED remains unclear. ${ }^{6}$ The effects of any health behaviour change intervention may, however, be best targeted to those with greatest readiness for change. A patient's readiness for change has been postulated as being an important predictor for success in quitting; it has therefore been argued that interventions should be tailored to match the patient's SOC for best success. ${ }^{11}$

Almost $70 \%$ of smokers in our sample wished to quit within the next 6 months. This is comparable to the Australian general adult population $(67 \%)^{19}$, and is consistent with previous ED-based research ${ }^{7,8}$ and related findings indicating a high receptiveness of ED patients to receiving advice on quitting. Among the $70 \%$ of smokers interested in quitting, nearly half $(23,45.1 \%)$ wished to do so within the following month, an indication of being in the 'preparation stage' and thus most receptive to actionoriented interventions such as goal setting. ${ }^{11}$ Despite this important finding, it is relevant to note that motivation to quit has been shown by others to be highly variable over time. ${ }^{20}$ 
Table 3. Number of participants according to tobacco use patterns

\begin{tabular}{llc}
\hline Item & Category & $\begin{array}{c}n(\% ; 95 \% \\
\text { confidence interval })\end{array}$ \\
\hline Number of & $\leq 10$ & $28(38.9 ; 28.5,50.5)$ \\
cigarettes a & $11-20$ & $27(37.5 ; 27.2,49.1)$ \\
day & $21-30$ & $12(16.7 ; 9.6,27.1)$ \\
& $\geq 31$ & $5(6.9 ; 2.6,15.6)$ \\
& Total & $\mathbf{7 2}(\mathbf{1 0 0 . 0})$ \\
\hline First cigarette & Within 5 minutes & $28(37.8 ; 27.6,49.2)$ \\
after waking & Within 6-30 minutes & $23(31.1 ; 21.7,42.4)$ \\
& Within 31-60 minutes & $5(6.8 ; 2.6,15.2)$ \\
& $>60$ minutes & $18(24.3 ; 15.9,35.3)$ \\
& Total & $\mathbf{7 4}(\mathbf{1 0 0 . 0})$ \\
\hline
\end{tabular}

\section{Intervention preferences}

Cessation intervention preferences are increasingly being recognised as important in smoking cessation. ${ }^{10,18}$ A cross-sectional, multicentre study revealed a high level of receptiveness to ED-initiated interventions, but heterogeneity in patient preferences for the type of intervention and style of counselling. ${ }^{18}$ NRT was most preferred (54\%) followed by linkage to hotlines or outpatient counselling (33-42\%). ED-based counselling was preferred by $33 \% .{ }^{18}$ Although we did not assess a broad range of intervention preferences, these results contrast with our own, in which $60 \%$ indicated willingness to undergo brief counselling in the ED. When given four possible interventions, having multisession face-to-face counselling was most preferred (40\%). Our sample preferred a greater level of engagement by patients in the cessation process. These data, combined with the prevalence of smoking among our sample, support a case for initiating smoking cessation programs for patients attending hospital.

A systematic review of interventions for smoking cessation in hospitalised patients revealed that counselling during hospitalisation with at least 1 month follow-up support produces sustained cessation, and counselling alone (without NRT) is effective. ${ }^{21}$ Others have demonstrated that Australian hospitalised patients are interested in commencing smoking cessation while in hospital22; this is especially relevant in smokefree hospitals where patients may have a higher motivation to quit because of perceived vulnerability, fewer opportunities to smoke and access to multiple healthcare providers.

It is essential to identify the most effective method to facilitate cessation initiated in the ED. Although the past decade has seen an emergence of ED smoking cessation research, studies have not been of adequate quality to definitively evaluate efficacy ${ }^{6}$ and, to our knowledge, none have been conducted in the Australian ED setting. One study found ED-based counselling to be as efficacious as that delivered in an outpatient setting. ${ }^{23}$ Similarly, a recent systematic review demonstrated that exposure to ED-based cessation interventions resulted in greater cessation rates than the US National Health Interview Survey average ${ }^{6}$, but that studies are highly heterogeneous in intervention type, follow-up timing, outcome assessment and control groups used. In a metaanalysis, ED-initiated tobacco control that incorporated motivational interviewing with booster telephone calls trended towards tobacco abstinence for up to 12 months. ${ }^{24}$

When extrapolated to the 8 million Australian ED attendances annually, our preliminary data suggest a potential to intervene on approximately 1.26 million smokers interested in quitting. With overcrowding in EDs and associated increasing clinician workload, public health screening and brief interventions are difficult without designated additional staff. Some interventions are labour intensive and have technology demands that may not be available in many hospitals. Clinicians should remember, however, that simply asking about smoking status and providing basic advice to quit may represent a powerful intervention in itself. There is scope to further explore how smoking cessation interventions could be readily incorporated into existing Australian ED workflow - interventions that are simple enough to be incorporated into standard care, but targeted enough to ensure cost-effectiveness. ED-initiated linkage to smoking cessation intervention may be achievable in Australia with computer-based interventions and internet-based resources, which have been successfully adopted for other populations.

\section{Limitations}

This study has several limitations. Although the study is strengthened by the use of point-prevalence methods, our brief period of sampling for each site may have introduced sampling bias brought about by factors such as seasonality, which some argue affects casemix. This study may have limited generalisability to all Australian EDs because it was limited to two sites and participants were selected based on convenience.

It is possible to verify exposure to tobacco smoke by measuring salivary cotinine. This was not undertaken for financial and logistical reasons within the short duration of an ED presentation. Participants may have been less inclined to self-report their smoking habits to the health professional conducting the survey because of perceived pressure to be socially desirable. Although Lowenstein ${ }^{8}$ has validated self-reported smoking at interview using a similar question to assess prevalence, others have found discrepancies in self-reported data compared with cotinine measurements. ${ }^{25}$ It is therefore possible that our data underestimate the prevalence of smoking and overestimate the proportion of those willing to quit. Our prevalence statistics may also be an underestimation because we excluded medically unstable or critically ill 
patients, and those who were intoxicated, had English language difficulties or left before assessment. Both serious illness and substance abuse have long been linked to increased rates of smoking.

Although we sought data regarding frequency of smoking, there was no option to specify whether participants smoked daily, and the study did not consider those that do not smoke cigarettes but instead smoke tobacco using alternative methods (e.g. pipe, vaporiser, electronic cigarette, shisha, hookah or cigars). These participants were not directed to respond in a specific way. This confounder may have been overcome through the use of a validated tool to assess smoking prevalence, and through a preliminary assessment of content validity. Finally, we undertook exploratory analyses without adjustment to the criterion for significance. A larger sample may permit multivariate assessment of the independent associations.

\section{Future research}

Further studies are required that use a longer sampling time frame across a larger sample of Australian EDs. Because $38 \%$ of smokers in our sample may have been highly receptive to action-oriented smoking cessation interventions, identification of the most efficacious, deliverable interventions for ED patients is needed. Determination of potential cost savings that can be made through ED-initiated interventions is also warranted.

\section{Conclusion}

Smoking is more prevalent among ED patients than statistics reported for the general population. Delivery of appropriate interventions initiated for smokers attending EDs should be considered following validation of these data.

\section{Acknowledgements}

We gratefully acknowledge the contribution of Dr Rodrigo Vargas who undertook all data collection for this study.

\section{Competing interests}

None declared

\section{Author contributions}

TW was responsible for the research design, drafting, data analysis and manuscript editing. ST, DT, and GJ were responsible for the research design and manuscript editing.

\section{References}

1. World Health Organisation. Why is tobacco a public health priority? Geneva: Tobacco Free Initiative; 2012 [cited 2012 Jun 14]. Available from: www.who.int/ tobacco/health_priority/en/print.html

2. Begg S, Vos T, Barker B, Stevenson C, Stanley L, Lopez A. The burden of disease and injury in Australia 2003. Canberra: Australian Institute for Health and Welfare; 2007 [cited 2015 May 19]. Available from: www. aihw.gov.au/publications/index.cfm/title/10317

3. Banks E, Joshy G, Weber MF, Liu B, Grenfell R, Egger S, et al. Tobacco smoking and all-cause mortality in a large Australian cohort study: findings from a mature epidemic with current low smoking prevalence. BMC Med. 2015;13:38.

4. Australian Institute of Health and Welfare. National Drug Strategy Household Survey 2013: tobacco smoking. Canberra: AlHW; 2015 [cited 2015 May 19]. Available from: www.aihw.gov.au/alcohol-and-other-drugs/ ndshs/2013/tobacco/

5. Scollo M, Winstanley M. Tobacco in Australia: Facts and issues. 4th ed. Melbourne: Cancer Council Victoria; 2012.

6. Pelletier JH, Strout TD, Baumann MR. A systematic review of smoking cessation interventions in the emergency setting. Am J Emerg Med. 2014;32(7):713-24.

7. Lynch A, Quigley P. ExHALED study: prevalence of smoking and harm levels in an emergency department cohort. Emerg Med Australas. 2010;22(4):287-95.

8. Lowenstein SR, Tomlinson D, Koziol-McLain J, Prochazka A. Smoking habits of emergency department patients: an opportunity for disease prevention. Acad Emerg Med. 1995;2(3):165-71.

9. Silagy C, Lancaster T, Stead L, Mant D, Fowler G. Nicotine replacement therapy for smoking cessation. Cochrane Database Syst Rev. 2004;3:CD000146.

10. Thomas D, Abramson MJ, Bonevski B, Taylor S, Poole SG, Weeks GR, et al. Quitting experiences and preferences for a future quit attempt: a study among inpatient smokers. BMJ Open. 2015;5(4):e006959.

11. Prochaska JO, Velicer WF. The transtheoretical model of health behavior change. Am J Health Promot. 1997;12(1):38-48.

12. Riemsma RP, Pattenden J, Bridle C, Sowden AJ, Mather L, Watt IS, Walker A. Systematic review of the effectiveness of stage based interventions to promote smoking cessation. BMJ 2003;326(7400):1175-7.

13. Fagerström KO, Heatherton TF, Kozlowski LT. Nicotine addiction and its assessment. Ear Nose Throat J. 1990;69(11):763-5.

14. Chaiton MO, Cohen JE, McDonald PW, Bondy SJ. The Heaviness of Smoking Index as a predictor of smoking cessation in Canada. Addict Behav. 2007;32(5):1031-42. 
15. Niaura R, Shadel WG. Assessment to inform smoking cessation treatment. In: Abrams DB, Niaura R, Brown RA, Emmons KM, Goldstein MG, Monti PM, editors. The tobacco dependence treatment handbook: a guide to best practices. New York: Guilford Press; 2003. p. 23-72.

16. Australian Bureau of Statistics. Australian Health Survey: first results, 2011-12. Canberra: Australian Bureau of Statistics; 2012 [cited 2015 May 19]. Available from: www.abs.gov.au/ausstats/abs@.nsf/Lookup/4364.0.55.00 1main+features12011-12

17. Health Intelligence Unit. Victorian Population Health Survey 2010. Melbourne: State Government of Victoria; 2012 [cited 2015 Aug 25]. Available from: www2.health. vic.gov.au/public-health/population-health-systems/ health-status-of-victorians/survey-data-and-reports/ victorian-population-health-survey/victorian-populationhealth-survey-2010

18. Choo EK, Sullivan AF, LoVecchio F, Perret JN, Camargo CA Jr, Boudreaux ED. Patient preferences for emergency department-initiated tobacco interventions: a multicentre cross-sectional study of current smokers. Addict Sci Clin Pract. 2012;7:4.

19. Walsh RA, Paul CL, Tzelepis F, Stojanovski E. Quit smoking behaviours and intentions and hard-core smoking in New South Wales. Health Promot J Austr. 2006;17(1):54-60.
20. Herzog T, Pokhrel P, Kawamoto CT. Short-term fluctuations in motivation to quit smoking in a sample of smokers in Hawaii. Subst Use Misuse. 2015;50(2):236-41.

21. Rigotti NA, Clair C, Munafo MR, Stead LF. Interventions for smoking cessation in hospitalised patients. Cochrane Database Syst Rev. 2012;5:CD001837.

22. George J, Taylor S, Hong T, Leung S, Nguyen J. A pilot study to investigate the scope for an inpatient cessation programme. Intern Med J. 2012;42(5):e80-3.

23. Ersel M, Kitapcioglu G, Solak ZA, Yuruktumen A, Karahalli E, Cevrim O. Are emergency department visits really a teachable moment? Smoking cessation promotion in emergency departments. Eur J Emerg Med. 2010;17:73-9.

24. Rabe GL, Wellmann J, Bago P, Busch M, Hense HW, Spies $C$, et al. Efficacy of emergency department-initiated tobacco control - systematic review and meta-analysis of randomized controlled trials. Nicotine Tob Res. 2013;15(3):643-55.

25. Connor Gorber S, Schofield-Hurwitz S, Hardt J, Levasseur G, Tremblay M. The accuracy of self-reported smoking: a systematic review of the relationship between self-reported and cotinine-assessed smoking status. Nicotine Tob Res. 2009;11(1):12-24.

\section{Copyright: (c)}

(C) 2016 Weiland et al. This article is licensed under the Creative Commons Attribution-NonCommercial-ShareAlike 4.0 International Licence, which allows others to redistribute, adapt and share this work non-commercially provided they attribute the work and any adapted version of it is distributed under the same Creative Commons licence terms. See: www.creativecommons.org/licenses/by-nc-sa/4.0/ 